\title{
Temporal trends of ${ }^{137} \mathrm{Cs}$ concentration in seawaters and bottom sediments in coastal waters around Japan: implications for the $K_{\mathrm{d}}$ concept in the dynamic marine environment
}

\author{
Masashi Kusakabe ${ }^{1}\left[\right.$ D Hoe Takata ${ }^{1,2}$ \\ Received: 24 September 2019 / Published online: 30 November 2019 \\ (c) The Author(s) 2019
}

\begin{abstract}
Radioactivity concentrations of ${ }^{137} \mathrm{Cs}$ in seawaters and bottom sediments have been measured in the coastal waters off all nuclear power plant sites in Japan. Sediment distribution coefficient $\left(K_{\mathrm{d}}\right)$ values obtained before the Fukushima Daiichi Nuclear Power Plant accident were variable and related to the specific surface area of the bottom sediment. A mathematical model suggested that before the accident the $K_{\mathrm{d}}$ values were in the transient state approaching a dynamic equilibrium with a converged $K_{\mathrm{d}}$ value of $1000-1600$. Based on a post-accident mathematical model, the apparent $K_{\mathrm{d}}$ reached the maximum of about $10^{4}$ and then decreased until now, converging to $6 \times 10^{3}$ on average.
\end{abstract}

Keywords ${ }^{137} \mathrm{Cs} \cdot K_{\mathrm{d}} \cdot$ Long-term monitoring $\cdot$ Fukushima $\cdot$ Seawater $\cdot$ Bottom sediment

\section{Introduction}

All nuclear power plants in Japan are located in alongshore areas. Coastal areas off these plant sites are basically a dynamic environment characterized by continuous supply of suspended matter from rivers, bottom sediments, and biological activities, and vigorous water mixing in both vertical and horizontal directions. Once pollutants such as artificial radionuclides are released to these areas, the fates of the nuclides are expected to be complicated accordingly. Due to the proximity of the plants to populated areas, the safety with respect to routine and accidental releases of radioactivity has been of great concern to not only close-by residents but also society at large.

Electronic supplementary material The online version of this article (https://doi.org/10.1007/s10967-019-06958-z) contains supplementary material, which is available to authorized users.

Masashi Kusakabe

kusakabe@kaiseiken.or.jp

1 Central Laboratory, Marine Ecology Research Institute, 300 Iwawada, Onjuku-machi, Chiba Prefecture 299-5105, Japan

2 Present Address: Institute of Environmental Radioactivity, Fukushima University, 1 Kanayagawa, Fukushima City, Fukushima Prefecture 960-1296, Japan
Ocean monitoring program to monitor level of artificial radionuclides in coastal waters around Japan (hereinafter regular monitoring) has been carried out since 1984 by the Marine Ecology Research Institute (MERI) under contract with the Ministry of Education, Culture, Sports, Science and Technology. In March 2011 after the Fukushima Dai-ichi Nuclear Power Plant (FDNPP) accident, comprehensive monitoring (hereinafter extended monitoring) was added to the program and has been carried out in the waters off Fukushima and nearby prefectures. In April 2013, control of the program was taken over by the Secretariat of the Nuclear Regulation Authority (NRA) of Japan. Targets of the monitoring program have been radioactivity in seawaters and bottom sediments.

During the almost 35 years of the monitoring, two nuclear accidents occurred: the Chernobyl Nuclear Power Plant (NPP) accident in 1986, which had only limited impacts on the Japanese environment, and the FDNPP accident in 2011. The regular monitoring provides an indispensable data set for the assessment of radioactivity in the marine environment before the FDNPP accident. And since the accident, the extended monitoring data together with those of the regular monitoring shed a light on the accident impacts on the marine environment and their temporal change.

The concentration ratio of an element in bottom sediments to that in overlying water, the sediment-water distribution coefficient $\left(K_{\mathrm{d}}\right)$, has been used in radiological 
assessment models in aquatic systems including freshwater and marine systems. The values have been estimated based on different methods such as field observations and laboratory experiments; basically, samples were collected once in field observations (e.g. [1, 2]) and laboratory experiments were carried out on a limited time scale of hours to weeks $[1,3]$, or at most months [4]. Stable elements and their artificial radioactive isotopes, that have been introduced since the 1940s, are expected to be distributed in bottom sediments differently; a significant amount ( $80 \%$, IAEA, 2004) of the stable nuclides in sediments exists as a non-exchangeable, immobile fraction, while most of the artificial radioactive nuclides in sediments are in a mobile fraction and able to undergo an exchange reaction with those in seawater. The recommended $K_{\mathrm{d}}$ values presented in the Technical Report Series No. 422 [5] vary significantly and that reflects not only the different methodologies used, but also other factors such as chemical and physical characteristics of sediments, hydrological and oceanographical settings, and proximity to contamination sources. Results from the above-mentioned monitoring program, however, give researchers a great opportunity to evaluate $K_{\mathrm{d}}$ values based on the systematic sampling scheme for more than three decades at fixed sampling sites around Japan. In addition, the FDNPP accident would allow quantification of $K_{\mathrm{d}}$ variation in variable situations such as the equilibrium condition, identification of the maximum impacts of the accident on the water-sediment system, and clarification of the recovery process to the pre-accident level.

In this paper, temporal changes of ${ }^{137} \mathrm{Cs}$ concentration in seawater and bottom sediment samples are presented based on the data obtained during the monitoring program (March 1984-January 2018); an emphasis is placed on the relationship between seawater and sediment ${ }^{137} \mathrm{Cs}$ concentrations. Discussion on spatial and temporal variations of the $K_{\mathrm{d}}$ values follows.

\section{Experimental}

Details of monitoring and measurement of ${ }^{137} \mathrm{Cs}$ concentrations for the regular monitoring have been reported previously [6-8]. Briefly, monitoring of seawaters and bottom sediments for artificial radionuclides in the coastal waters off nuclear power plants started in 1984. The samplings have been carried out once a year at 15 areas which each had
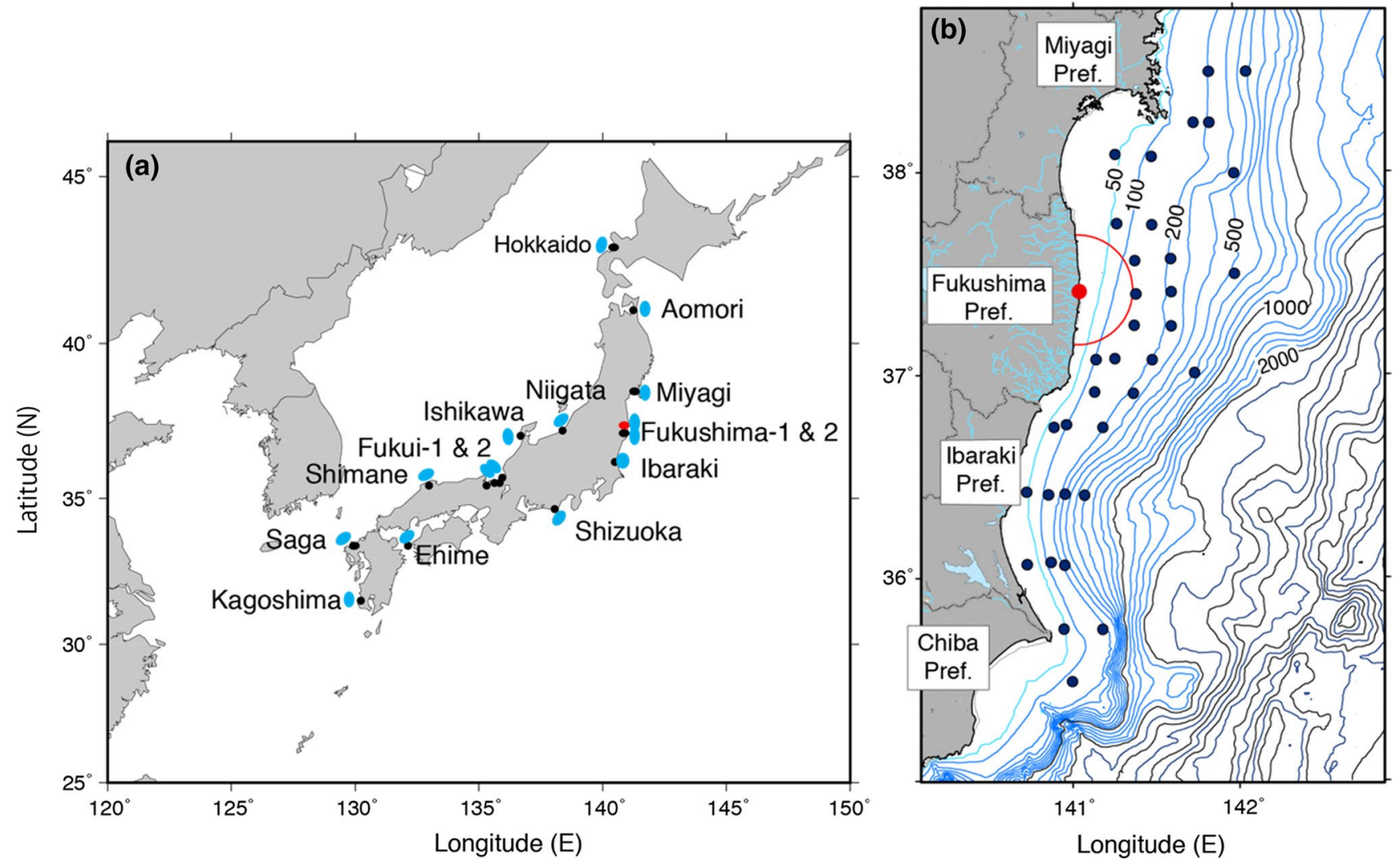

Fig. 1 a Monitoring area and sampling sites for the regular monitoring. Blue areas are monitoring areas with 4 sampling sites, which are visited once a year. Black dots indicate the locations of nuclear power

plants, b sampling sites for the extended monitoring. The sampling sites (black dot) are visited 4 times a year. The red circle is at $30 \mathrm{~km}$ radius from the FDNPP 
four sampling sites (Fig. 1a). Surface seawater (0-1 m water depth) and bottom seawater samples (mostly ca. $10 \mathrm{~m}$ above the seafloor) were collected at each site. Water samples in intermediate depths were also collected at the sites with a greater water depth $(>$ ca. $100 \mathrm{~m})$. Activities of ${ }^{137} \mathrm{Cs}$ in seawaters were obtained mainly by beta ray measurement after separation and purification with ammonium molybdophosphate (AMP) and chloroplatinate. Some samples were measured by gamma spectrometry after separation and purification with AMP. Since the FDNPP accident, only gamma spectrometry has been used. Bottom sediments were taken using a box corer, and a surface layer of $3 \mathrm{~cm}$ thickness (designated as surface sediment) was retrieved for analysis by gamma spectrometry.

Quality of the data was guaranteed at least once a year based on calibration of the gamma ray spectrometers by using the certified reference material provided by the Japan Calibration Service System. In addition, that was also routinely monitored every a few weeks by using in-house substandard materials. Uncertainties of the data were estimated based on counting statistics of $1 \sigma$. The detection limits were calculated to be three times of a value of the counting statistics error.

From the 2011 FDNPP accident to present, the extended monitoring has been carried out in the waters off Fukushima and near-by prefectures (Fig. 1b). In the early stage of the monitoring (March-August 2011), sampling sites were limited. Since September 2011, 32 sites have been set where surface and bottom seawaters, and surface sediments have been collected four times a year. Details of the extended monitoring have been given in the literatures [8-12].

\section{Results and discussion}

The data obtained by the monitoring program have been reported to the related governmental authorities as official printed documents written in Japanese every year by the MERI. Since the accident, the data derived from the extended monitoring have been uploaded as well on the NRA website [13] as soon as they became available. In the meantime, some of the data have been published in the scientific journals $[6-12,14]$. The data presented in the following sections were derived from the scientific journals and the official documents. Those in the documents were compiled in Supplementary Tables S1-S4 with relevant parameters unless they have been published elsewhere in scientific journals.
Temporal changes of activity concentrations of ${ }^{137} \mathrm{Cs}$ in surface and bottom seawaters

Prior to the Chernobyl NPP accident in 1986, reported ${ }^{137} \mathrm{Cs}$ activity concentrations in the surface water samples ranged from 3.3 to $5.6 \mathrm{mBq} \mathrm{L}^{-1}$ with an average of $4.1 \mathrm{mBq} \mathrm{L}^{-1}$ [8]. After the Chernobyl accident, ${ }^{137} \mathrm{Cs}$ concentrations in the surface water samples increased to a maximum of $10 \mathrm{mBq} \mathrm{L}^{-1}$. In the following year, 1987 , the ${ }^{137} \mathrm{Cs}$ activity concentrations returned to the level of previous years, $3.3-4.8 \mathrm{mBq} \mathrm{L}^{-1}$. Since then, the concentrations have decreased exponentially; they were in a range of 1.1-1.9 mBq L${ }^{-1}$ with an arithmetic mean of $1.5 \pm 0.2 \mathrm{mBq} \mathrm{L}^{-1}$ as of May-June 2010 .

The ${ }^{137} \mathrm{Cs}$ activity concentrations in the bottom water samples are plotted in Fig. 2a. Their temporal trend was similar to that of the surface water except for the year 1986 when the impact of the Chernobyl accident did appear for the surface water, but not in the bottom water. Geographical variation of the concentrations among the sites has been reflected at the sampling depths; deeper waters had lower concentrations due to the intrusion of deep water from the open ocean with lower concentrations. Overall, the concentrations had steadily decreased with time prior to the FDNPP accident. The arithmetic mean of ${ }^{137} \mathrm{Cs}$ activity concentrations in the bottom seawater samples was $4.3 \pm 0.4 \mathrm{mBq} \mathrm{L}^{-1}$ in 1984 and it had decreased to $1.4 \pm 0.3 \mathrm{mBq} \mathrm{L}^{-1}$ in 2010 .

Following the accident at the FDNPP, ${ }^{137} \mathrm{Cs}$ concentrations in surface seawater jumped up several orders of magnitudes. For example, April 15, 2011 had the highest value in the extended monitoring $\left(186 \mathrm{~Bq} \mathrm{~L}^{-1}\right)$ for surface water sampled about $30 \mathrm{~km}$ from the accident site [9]; that was a five orders of magnitude increase from the pre-accident value of $1.6 \pm 0.3 \mathrm{mBq} \mathrm{L}^{-1}$ (averaged over the 2006-2010 period for data off the Fukushima coast). After that, the concentrations decreased exponentially until around September 2011 , following a declining trend at a slow rate $[9,12,14$, 15]. As of June 2018, the arithmetic average of ${ }^{137} \mathrm{Cs}$ in surface seawater was $2.3 \pm 0.3 \mathrm{mBq} \mathrm{L}^{-1}$ in the areas marked Miyagi, Fukushima 1 and 2 and Ibaraki in Fig. 1a. The concentrations of ${ }^{137} \mathrm{Cs}$ in the bottom water followed the same trend as surface water to a lesser extent (Figs. 2a, 3a). The arithmetic means of concentrations of ${ }^{137} \mathrm{Cs}$ in surface and bottom seawaters in the extended monitoring were 1.92 and $1.86 \mathrm{mBq} \mathrm{L}^{-1}$ as of January 2019, respectively (Fig. 3a). Continuing input of ${ }^{137} \mathrm{Cs}$ from the accident site has been reported $[12,16,17]$. The higher concentrations than the pre-accident values as of 2018 should be ascribed to this continuous release from the accident site. 


\section{Temporal changes of ${ }^{137} \mathrm{Cs}$ activity concentrations in bottom sediments}

While the ${ }^{137}$ Cs activity concentrations in the bottom sediments have a much wider geographical variation than those in bottom seawater, reflecting wide variation of physical and chemical characteristics of the sediments such as grain size and organic matter content among others which may affect the sediment ${ }^{137} \mathrm{Cs}$ concentrations [e.g., 12], their temporal changes showed a similar declining trend in bottom seawater (Fig. 2a). On the basis of geometric mean, the concentration declined from $2.9 \mathrm{~Bq} \mathrm{~kg}^{-1}$ in 1984 to $1.8 \mathrm{~Bq} \mathrm{~kg}^{-1}$ in 2010 . No elevated concentration of ${ }^{137} \mathrm{Cs}$ that originated from the Chernobyl accident in 1986 was observed in the sediments.

Figure $2 \mathrm{~b}$ indicates the temporal trend of ${ }^{137} \mathrm{Cs}$ in bottom sediments in the coastal areas around Japan. Three areas (Miyagi, Fukushima, and Ibaraki) close to the FDNPP accident site increased by a maximum of two orders of magnitudes, and this increase appeared later than that of bottom seawater. And their declining rates were much slower than those for bottom seawater. In Fig. 3b, trends based on more detailed sampling, i.e., the extended monitoring,
Fig. 2 Temporal changes of ${ }^{137} \mathrm{Cs}$ activity concentrations in a bottom water, $\mathbf{b}$ surface sediment and $\mathbf{c} K_{\mathrm{d}(\mathrm{a})}$ in the regular monitoring areas. The data derived from areas close to the FDNPP (Miyagi, Fukushima, and Ibaraki) are shown in lines. The black dotted lines indicate the time of the FDNPP accident

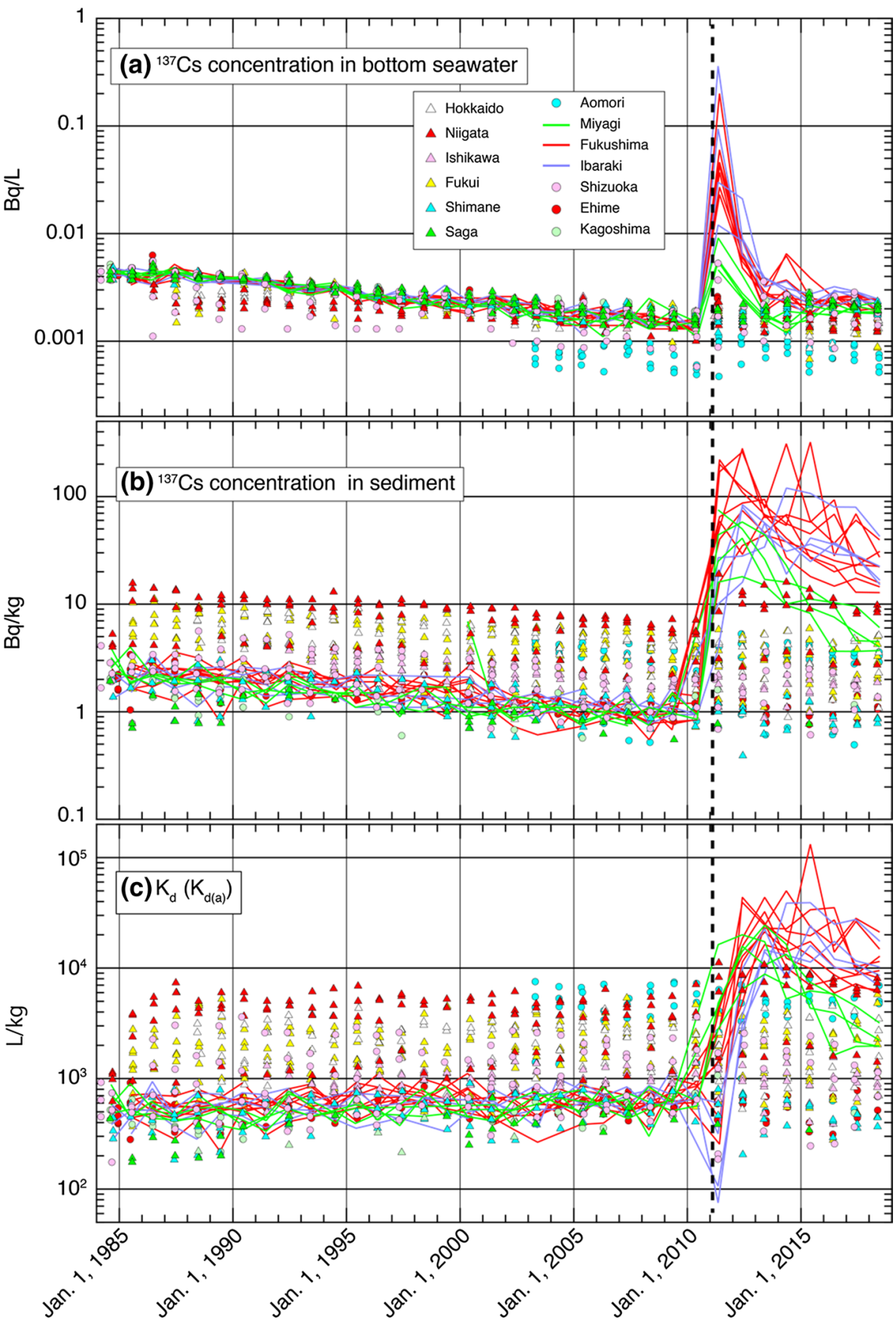




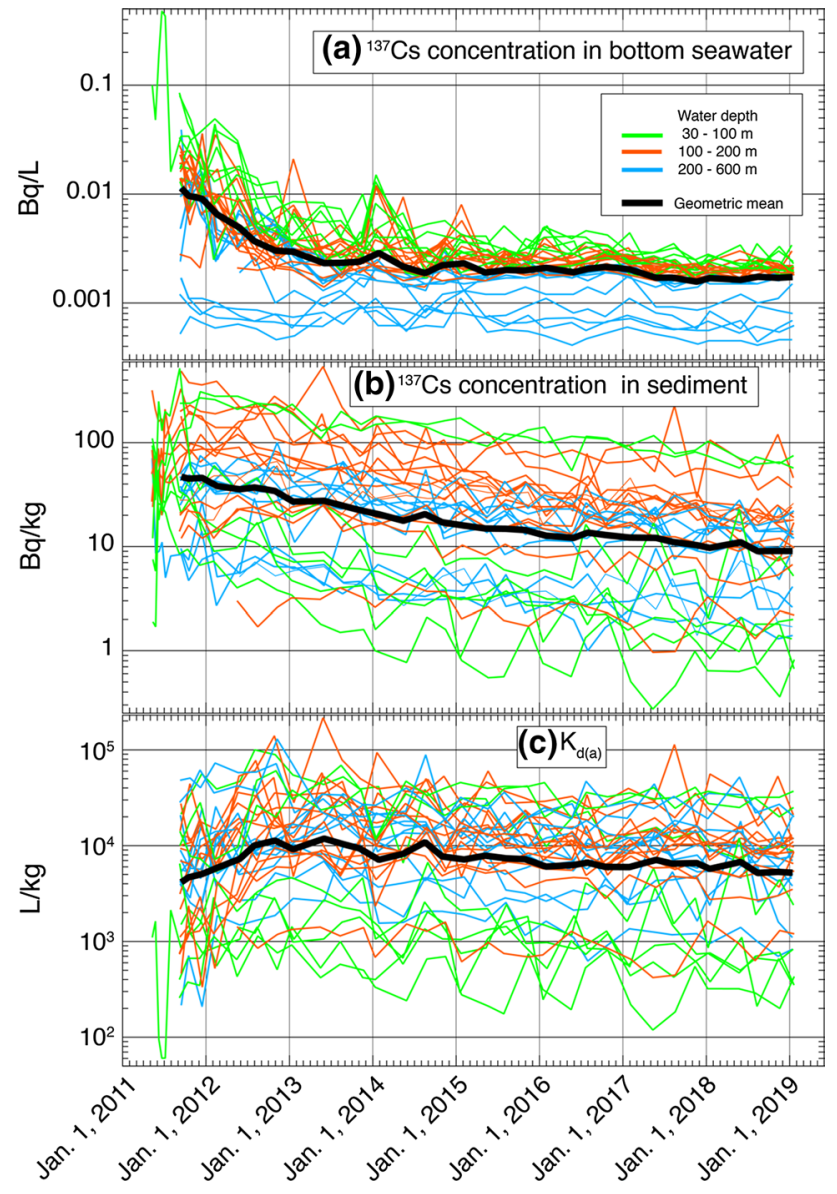

Fig. 3 Temporal changes in ${ }^{137} \mathrm{Cs}$ activity concentrations in bottom seawater (a) and sediment (b), and of $K_{\mathrm{d}(\mathrm{a})}(\mathbf{c})$ in the extended monitoring areas

showed that in less than one year after the accident, the ${ }^{137} \mathrm{Cs}$ concentrations in the sediments reached the maximum of $580 \mathrm{~Bq} \mathrm{~kg}^{-1}$ [10]. After that, the concentrations, in general, decreased with time. The declining trend seemed to be ongoing as of January 2019. Kusakabe et al. [11] analyzed the declining trend showing that abundance of ${ }^{137} \mathrm{Cs}$ in the surface sediments collected in the extended monitoring area (Fig. 1b) decreased from $4.57 \times 10^{13} \mathrm{~Bq}$ in September 2011 to $1.09 \times 10^{13} \mathrm{~Bq}$ in February 2016 with an effective half-life of 2.3 year. However, the declining rates at each site varied significantly. They depended on grain size of the sediments: that is, ${ }^{137} \mathrm{Cs}$ in sediments with larger grain size have been decreasing faster than those with smaller grain size.

\section{Effective half-life of ${ }^{137} \mathrm{Cs}$ in surface and bottom seawaters and bottom sediments before the accident}

The declining trend of ${ }^{137} \mathrm{Cs}$ concentrations in surface and bottom seawaters and bottom sediments shown above was quantified based on the assumption that the ${ }^{137} \mathrm{Cs}$ concentrations decrease exponentially with time, i.e.,

$C_{s}=C_{s 0} \times e^{-\gamma t}$

where $C_{s}, C_{s 0}, \gamma$, and t are measured ${ }^{137} \mathrm{Cs}$ concentration $\left(\mathrm{Bq} \mathrm{L}^{-1}\right.$ or $\left.\mathrm{Bq} \mathrm{kg}{ }^{-1}\right)$, initial ${ }^{137} \mathrm{Cs}$ concentration, decrease rate (year ${ }^{-1}$ ) and time (year), respectively. Equation (1) was fitted to the data obtained from 1984 to 2010 to evaluate $\gamma$. An index for the declining trend can be expressed as an effective half-life, which was calculated as follows.

effective half-life (year) $=\ln (2) / \gamma$

Effective half-life of ${ }^{137} \mathrm{Cs}$ in bottom water was calculated to be 17.3 year on average in the range from 12.8 to 25.0 year in bottom waters in all the monitoring areas (Table 1). Relatively short half-lives were estimated from the Miyagi, Fukushima, and Ibaraki areas; they ranged from 12.8 to 17.4 year. Long effective half-lives of more than

Table 1 Effective half-lives of ${ }^{137} \mathrm{Cs}$ in seawater and sediment (19842010)

\begin{tabular}{|c|c|c|c|c|}
\hline \multirow[t]{2}{*}{ Area } & \multicolumn{2}{|c|}{ Bottom water } & \multicolumn{2}{|c|}{ Sediment } \\
\hline & $\operatorname{AM}(y)$ & Range & $\mathrm{AM}(y)$ & Range \\
\hline \multicolumn{5}{|l|}{ Pacific Ocean } \\
\hline Aomori & 19.0 & $13.2-25.0$ & 14.3 & $10.3-21.5$ \\
\hline Miyagi & 14.6 & $12.8-16.2$ & 18.1 & $16.3-22.9$ \\
\hline Fukushima & 15.6 & $14.3-17.4$ & 18.1 & $12.3-23.5$ \\
\hline Ibaraki & 15.8 & $14.5-16.7$ & 23.4 & $17.0-28.8$ \\
\hline Shizuoka & 15.8 & $13.7-17.0$ & 28.0 & $15.2-41.4$ \\
\hline Ehime & 16.2 & $15.9-16.5$ & 21.0 & $19.0-24.8$ \\
\hline Kagoshima & 16.9 & $15.4-18.6$ & 34.6 & $24.1-55.1$ \\
\hline \multicolumn{5}{|l|}{ Japan Sea } \\
\hline Hokkaido & 22.2 & $21.0-22.7$ & 23.1 & $20.7-26.7$ \\
\hline Niigata & 20.8 & $16.7-23.6$ & 34.4 & $29.0-49.2$ \\
\hline Ishikawa & 16.1 & $14.3-17.3$ & 19.7 & $16.1-25.9$ \\
\hline Fukui & 18.5 & $16.1-23.5$ & 23.7 & $18.3-32.9$ \\
\hline Shimane & 17.5 & $16.2-18.6$ & 27.2 & $19.2-42.2$ \\
\hline Saga & 16.2 & $15.5-16.8$ & 27.3 & $27.3-27.3$ \\
\hline $\begin{array}{l}\text { Miyagi, Fukushima, } \\
\text { Ibaraki }\end{array}$ & 15.4 & $12.8-17.4$ & 19.4 & $12.3-28.8$ \\
\hline Sites in the pacific & 15.8 & $12.8-25.0$ & 23.0 & $10.3-55.1$ \\
\hline Sites in the Japan Sea & 18.5 & $14.4-23.6$ & 24.2 & $16.1-49.2$ \\
\hline All the areas & 17.3 & $12.8-25.0$ & 23.6 & $10.3-55.1$ \\
\hline
\end{tabular}

$A M$ arithmetic mean 
20 year for bottom waters were obtained for Hokkaido and Niigata areas, which are in the northern part of the Japan Sea. Analyzing the data obtaining in 1983-2016, Takata et al. [8] ascribed their long half-lives to the prevailing slow exchange of water with the surrounding areas.

Effective half-life of ${ }^{137} \mathrm{Cs}$ activity concentrations in the surface water of $16.5 \pm 0.9$ year has also been estimated in the open ocean from the 1950 s to the 1990 s for the western North Pacific in the middle latitudes [18]. The temporal trend of ${ }^{137} \mathrm{Cs}$ activity concentrations in coastal seawaters is assumed to be controlled by physical processes in the open ocean because: (1) the declining trend of surface ${ }^{137} \mathrm{Cs}$ activity concentration in the open ocean is mainly controlled by physical decay and vertical mixing [19]; (2) there is no physical barrier to prevent active water exchange between coastal areas and the open ocean; and (3) the effective halflives in coastal areas are similar to those of the open ocean.

The effective half-lives for the sediments were calculated to be from 10.3 to 55.1 years with the average of 23.6 years in all monitoring areas, and from 12.3 to 28.8 year with the average of 19.4 years in Miyagi, Fukushima, and Ibaraki Prefectures (regular monitoring area; Fig. 1a) (Table 1). Due to possible biological activity in the sediments the surface ${ }^{137} \mathrm{Cs}$ may have been trasported down to the deeper layer leading to reduction of ${ }^{137} \mathrm{Cs}$ concentration in the surface sediments. Thus, the effective half-lives may be calculated to be smaller values in sites where the biological activity is vigorous. Kuakabe et al. [11], however, studied the vertical profiles of ${ }^{137} \mathrm{Cs}$ in the sediments in the waters off Fukushima

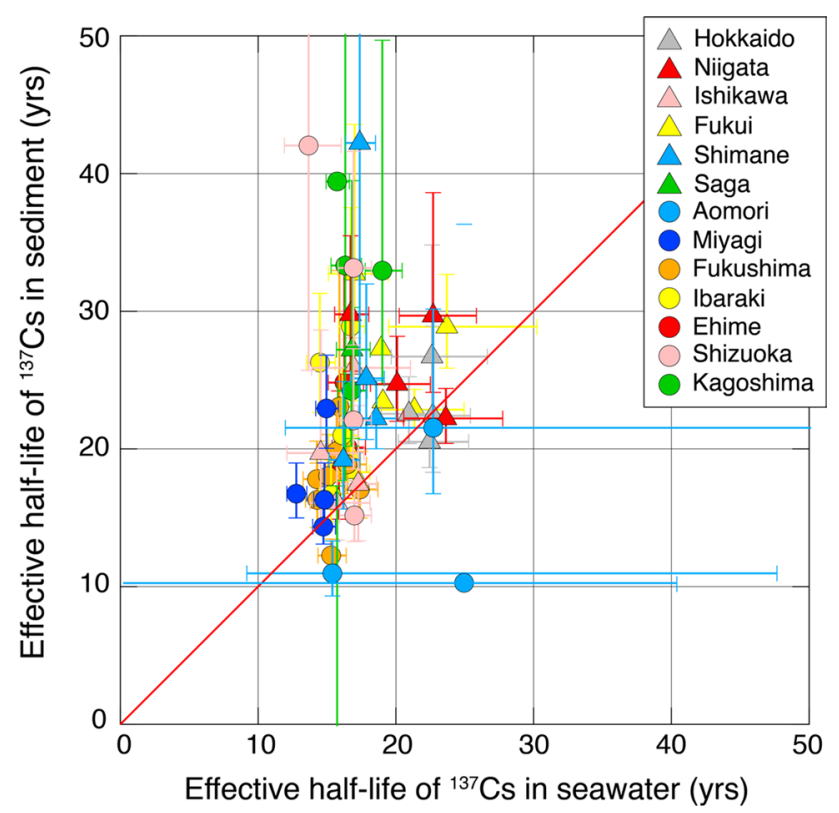

Fig. 4 Relationship between effective half-lives of ${ }^{137} \mathrm{Cs}$ in bottom seawater and surface sediment. All data prior to the FDNPP accident. A red line indicates a 1:1 line prefecture and suggested that downward transportation of ${ }^{137} \mathrm{Cs}$ in the sediments by biological activity does not play a significant role in the post-depositional distribution of ${ }^{137} \mathrm{Cs}$.

A comparison was made between effective half-lives in bottom seawater and surface sediment in Fig. 4. The effective half-lives in bottom sediment samples were longer than in seawater samples, deviating from a 1:1 line. Averages of ${ }^{137} \mathrm{Cs}$ in bottom waters and sediments in the coastal water around Japan were 17.3 and 23.6 years, respectively (Table 1). The data on the effective half-lives from the Pacific sites and Japan Sea sites did not differ significantly from each other. The long-term monitoring, thus, implied the marine system around Japan in general has not been in equilibrium and exchange of ${ }^{137} \mathrm{Cs}$ has not been reversible and instantaneous on a long-term basis. A lack of equilibrium may lead to a temporal change in $K_{\mathrm{d}}$ values as discussed in the sections below.

\section{Sediment distribution coefficient $\left(K_{d}\right)$ in the coastal waters}

The $K_{\mathrm{d}}$ value is defined as the ratio of concentration per mass of particulate matter to concentration per mass or per unit volume of water [5]. In principle, $K_{\mathrm{d}}$ can be evaluated only in a closed system which contains well-mixed seawater and sediment, both in equilibrium, i.e., no changes of concentration with time. However, such a situation is hardly to be found in nature, especially in coastal waters which are characterized by such conditions as a high load of suspended particles derived from biological activities, river runoffs and resuspension of sediments, and vigorous water mixing (vertical and horizontal). While $K_{\mathrm{d}}$ values evaluated on the basis of field observations of stable elements and naturally occurring radionuclides may be reliably assumed to be values under the equilibrium condition, those for artificial radionuclides are seldom for the equilibrium condition; inputs of artificial radionuclides to the marine environment have been geographically scattered and sporadic for the last eight decades. Hereafter, two kinds of sediment distribution coefficients are used, $K_{\mathrm{d}}$ and $K_{\mathrm{d}(\mathrm{a})}$; the former is used for the pre-accident situation, which can be regarded to be under a quasi-equilibrium (see the following sections for detail), and the latter is an apparent $K_{\mathrm{d}}$ that is used for the post-accident situation and may not follow the assumptions inherent in the theoretical $K_{\mathrm{d}}$ definition that the equilibrium and/or that the exchanges are wholly reversible and instantaneous [20]. If $K_{\mathrm{d}}$ for the system under the equilibrium condition is known beforehand, $K_{\mathrm{d}(\mathrm{a})}$ calculated for the system later could serve as a measure of departure from the equilibrium, and it may be of help for establishing a time scale for the system to be restored to its original state. 


\section{Geographical variation of $K_{\mathrm{d}}$}

The $K_{\mathrm{d}}$ values were calculated for all the sites for the regular monitoring (Fig. 1a) prior to the FDNPP accident from 1984 to 2010, and summarized in Table 2 and Fig. 5. They ranged quite widely from 175 at Shizuoka to 7541 at Aomori; the $K_{\mathrm{d}}$ geometric mean and median were 923 and 719, respectively. One of the reasons for a greater than 40 -fold variation in $K_{\mathrm{d}}$ might be physical characteristics of the bottom sediments. He and Walling [21] demonstrated a quantitative

Table 2 Summary of $K_{\mathrm{d}}$ values in the coastal areas around Japan (1984-2010)

\begin{tabular}{lrrrlc}
\hline Area & GM & Median & Maximum & Minimum & No. of data \\
\hline Pacific Ocean & & & & & \\
Aomori & 3541 & 4667 & 7541 & 488 & 31 \\
Miyagi & 536 & 525 & 900 & 300 & 96 \\
Fukushima & 597 & 596 & 1111 & 219 & 186 \\
Ibaraki & 573 & 581 & 1214 & 270 & 92 \\
Shizuoka & 937 & 842 & 3621 & 175 & 98 \\
Ehime & 544 & 544 & 919 & 281 & 80 \\
Kagoshima & 414 & 422 & 737 & 214 & 42 \\
Japan Sea & & & & & \\
Hokkaido & 1809 & 2167 & 4333 & 425 & 89 \\
Niigata & 3114 & 4000 & 7360 & 620 & 105 \\
Ishikawa & 921 & 947 & 1667 & 500 & 77 \\
Fukui & 1512 & 1556 & 6000 & 367 & 200 \\
Shimane & 488 & 497 & 905 & 183 & 78 \\
Saga & 341 & 379 & 667 & 175 & 27 \\
All the areas & 923 & 719 & 7541 & 175 & 1201 \\
\hline
\end{tabular}

$G M$ geometric mean relationship between adsorbed ${ }^{137} \mathrm{Cs}$ on soil particles and the particle surface area. Thus, $K_{\mathrm{d}}$ is expected to be closely related to the grain size expressed as specific surface area of the sediment.

Physical characteristics of the bottom sediments expressed as (silt + clay) contents and specific surface areas were quite variable among the monitoring sites compared to their temporal changes at each site (Tables 3, S5). For example, (silt + clay) contents varied from 1 to $100 \%$ in the sediments in the coastal waters. Even in a same sampling area, the contents varied significantly. Accordingly the specific surface area of the sediments ranged also widely from 0.03 to $0.7 \mathrm{~m}^{2} \mathrm{~g}^{-1}$. In Fig. 6 , the $K_{\mathrm{d}}$ values are plotted against specific surface area data, which were only available for the samples taken from 2016 to 2018 (Table 3). The data were fitted to a power function. Even though timings of sampling for both parameters did not match, a best-fit curve with a coefficient of determination $\left(r^{2}=0.78\right)$ was obtained as follows:

$K_{\mathrm{d}}=1.12 \times 10^{4} S^{1.66}$

where $S$ is a specific surface area $\left(\mathrm{m}^{2} \mathrm{~g}^{-1}\right)$ of bottom sediment. This relationship suggests that spatial variation of $K_{\mathrm{d}}$ in the coastal waters around Japan reflects the grain size distribution in the sediments. The notably highest $K_{\mathrm{d}}$ values from Aomori may be ascribed to the relatively large specific surface area of sediment there compared with most of the other monitoring sites (Table 3).

The IAEA [5] recommended the $K_{\mathrm{d}}$ value of Cs for an ocean margin is $4 \times 10^{3}$. Apparent differences of the $K_{\mathrm{d}}$ values between the recommended one and measured ones shown above may arise from the difference in the ways to
Fig. 5 Summary of the $K_{\mathrm{d}}$ $\left(\mathrm{L} \mathrm{kg}^{-1}\right)$ distribution in the coastal water around Japan (1984-2010). The boxwhisker-plot shows minimums, lower quartiles, medians, upper quartiles and maximums

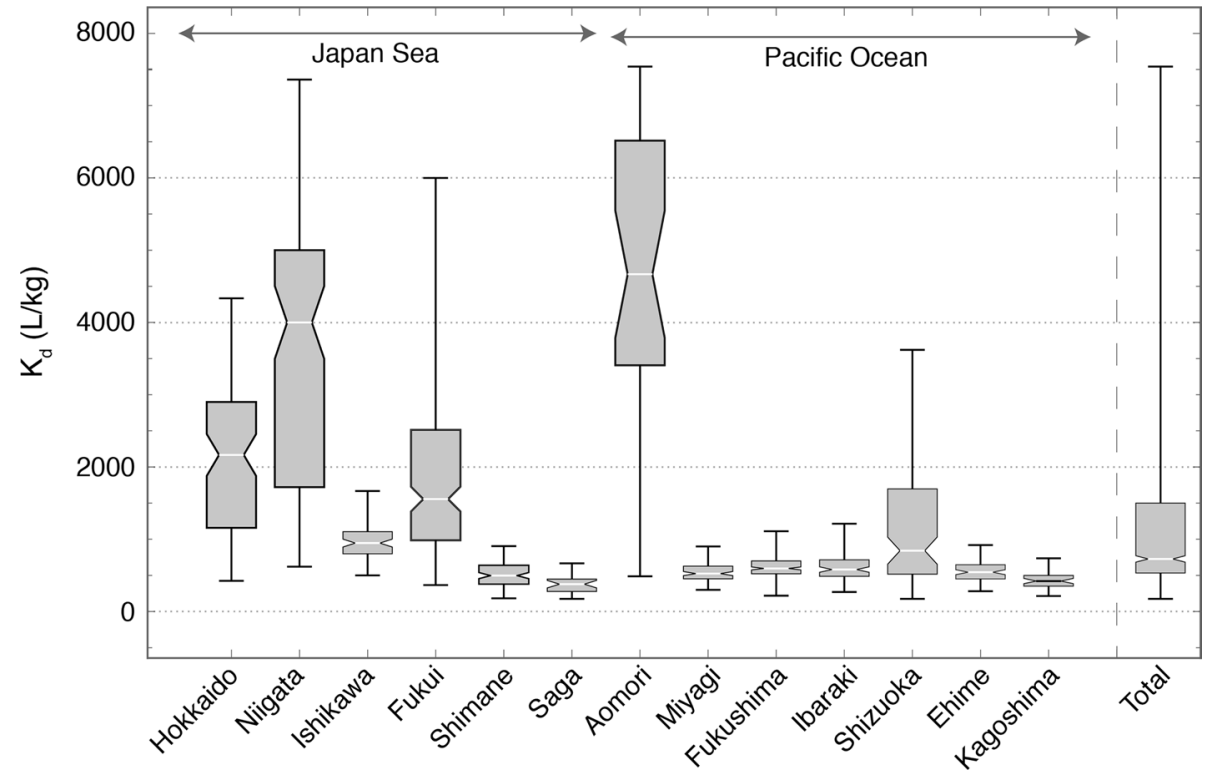


Table 3 Summary of particle size analysis. Data adapted from Kudo et al. (in prep.)

\begin{tabular}{lcclll}
\hline Area & \multicolumn{2}{l}{$\begin{array}{l}\text { (Silt+clay) contents } \\
(\%)\end{array}$} & & \multicolumn{2}{l}{$\begin{array}{l}\text { Specific surface area } \\
\left(\mathrm{m}^{2} \mathrm{~g}^{-1}\right)\end{array}$} \\
\cline { 2 - 3 } \cline { 6 - 7 } & Range & AM & & Range & AM \\
\hline Aomori & $7-82$ & 55 & & $0.12-0.53$ & 0.32 \\
Miyagi & $16-49$ & 28 & & $0.10-0.32$ & 0.17 \\
Fukushima & $13-64$ & 35 & & $0.12-0.34$ & 0.19 \\
Ibaraki & $17-80$ & 39 & & $0.13-0.27$ & 0.18 \\
Shizoku & $2-87$ & 48 & & $0.07-0.50$ & 0.26 \\
Ehime & $3-22$ & 13 & & $0.08-0.20$ & 0.14 \\
Kagoshima & $2-34$ & 17 & & $0.11-0.26$ & 0.18 \\
Hokkaido & $12-97$ & 69 & & $0.10-0.56$ & 0.32 \\
Niigata & $21-100$ & 81 & & $0.22-0.70$ & 0.43 \\
Ishikawa & $20-71$ & 51 & & $0.16-0.31$ & 0.24 \\
Fukui & $16-100$ & 78 & & $0.14-0.50$ & 0.34 \\
Shimane & $5-41$ & 21 & & $0.09-0.23$ & 0.16 \\
Saga & $1-22$ & 11 & & $0.03-0.24$ & 0.14 \\
Miyagi, Fuku- & $13-80$ & 34 & & $0.10-0.34$ & 0.18 \\
shima, Ibaraki & & & & & \\
\hline
\end{tabular}

Analyses were done for the samples collected in 2016-2018

$A M$ arithmetic mean

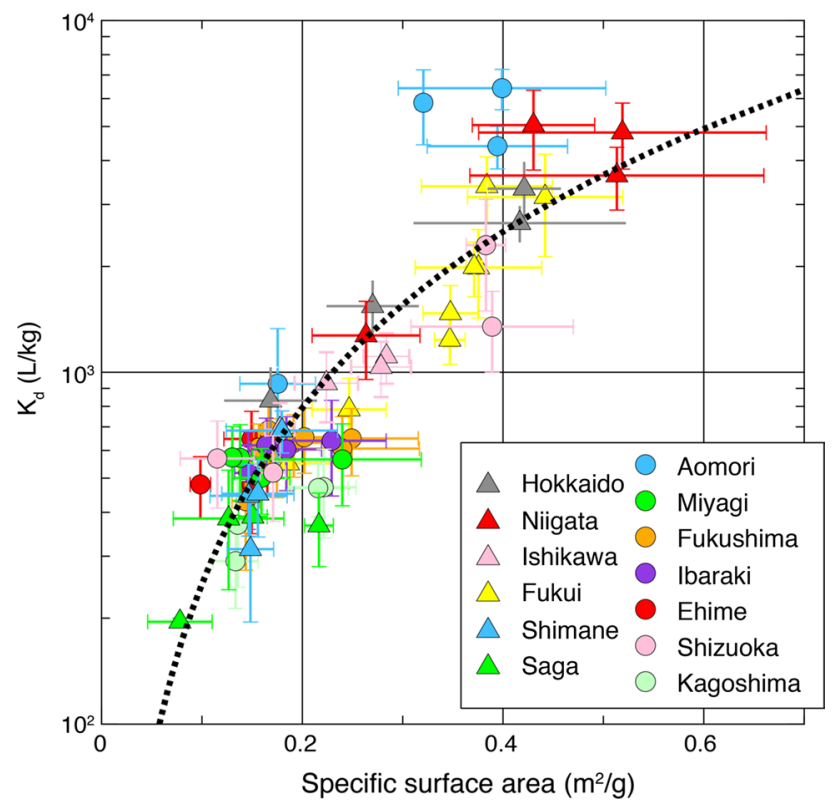

Fig. 6 Relationship between $K_{\mathrm{d}}$ and specific surface area of the sediments. A dotted line indicates a regression line fitted to the data (see text for detail). All data prior to the FDNPP accident (1984-2010)

estimate them: the former was based on stable Cs and the latter was based on the measured ${ }^{137} \mathrm{Cs}$ in seawater and sediment. Inevitable inclusion of immobile, stable Cs in sediments may result in the higher value for the estimate from measurements. Kershaw et al. [22] reported $K_{\mathrm{d}}$ values in the Irish Sea were $\sim 10^{3}$. MacKenzie et al. [23], however, estimated $K_{\mathrm{d}}$ values in the Irish Sea to be even higher, i.e., $10^{4}-10^{5}$. They attributed the higher values to the difference in estimation of $K_{\mathrm{d}}$ values; the values were estimated for the sediment-interstitial water system. Differences in oceanographic settings, and temporal flux and its change in ${ }^{137} \mathrm{Cs}$ discharge, as well as mineralogy, will result in the significant difference of $K_{\mathrm{d}}$ values. While the Irish Sea is a semi-closed sea facing the Sellafield nuclear fuel reprocessing plant that has been discharging radionuclides such as ${ }^{137} \mathrm{Cs}$ since the 1950s, most monitoring areas around Japan are in the coastal areas directly facing the open ocean where only global fallout ${ }^{137} \mathrm{Cs}$ dominates.

\section{Temporal change of $K_{d}$ before the FDNPP accident}

As can be inferred from the relationship of effective halflives between bottom seawater and bottom sediments (Fig. 4), the geometric means of $K_{\mathrm{d}}$ in the coastal waters around Japan increased from 640 in 1984 to 1400 in 2010 (Fig. 7). And those in the waters off Miyagi, Fukushima, and Ibaraki Prefectures increased from 520 to 680 in the same period. Uchida and Tagami [24] compiled data of ${ }^{137} \mathrm{Cs}$ concentrations in seawater and sediment from 1964 to 2010 in the coastal waters around Japan and calculated $K_{\mathrm{d}}$ values, for which geometric means were then summarized for every ten years, starting with 1970. Except for 1964-1969, the geometric mean values have been in an increasing trend from 260 to 580. Uchida and Tagami [25] suggested that ${ }^{137} \mathrm{Cs}$ partially became less mobile after a long contact period in sediment. During 1964-1969, the impact of global fallout on the environment should be the highest leading to the largest $K_{\mathrm{d}}$ values.

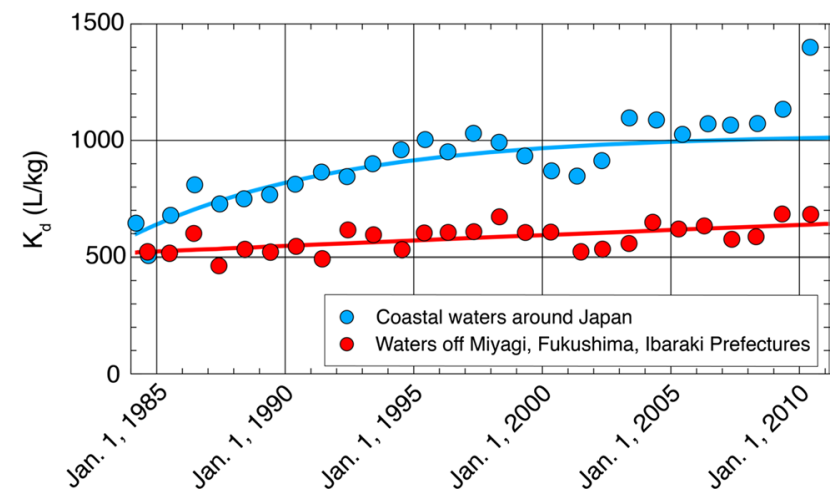

Fig. 7 Temporal change of the geometric mean of $K_{\mathrm{d}}$ 's $\left(\mathrm{L} \mathrm{kg}^{-1}\right)$ in the regular monitoring areas (1984-2010). The lines indicate bestfit curves for the geometric means at all of the monitoring data sites (blue) and those in the three prefectures only (red) 
Fig. 8 Schematic diagram of ${ }^{137} \mathrm{Cs}$ migration in the ocean. The yellow arrows indicate the migration of ${ }^{137} \mathrm{Cs}$ before the accident and the red arrow shows the additional pathway for the nuclide after the FDNPP accident (a) Regular

monitoring area

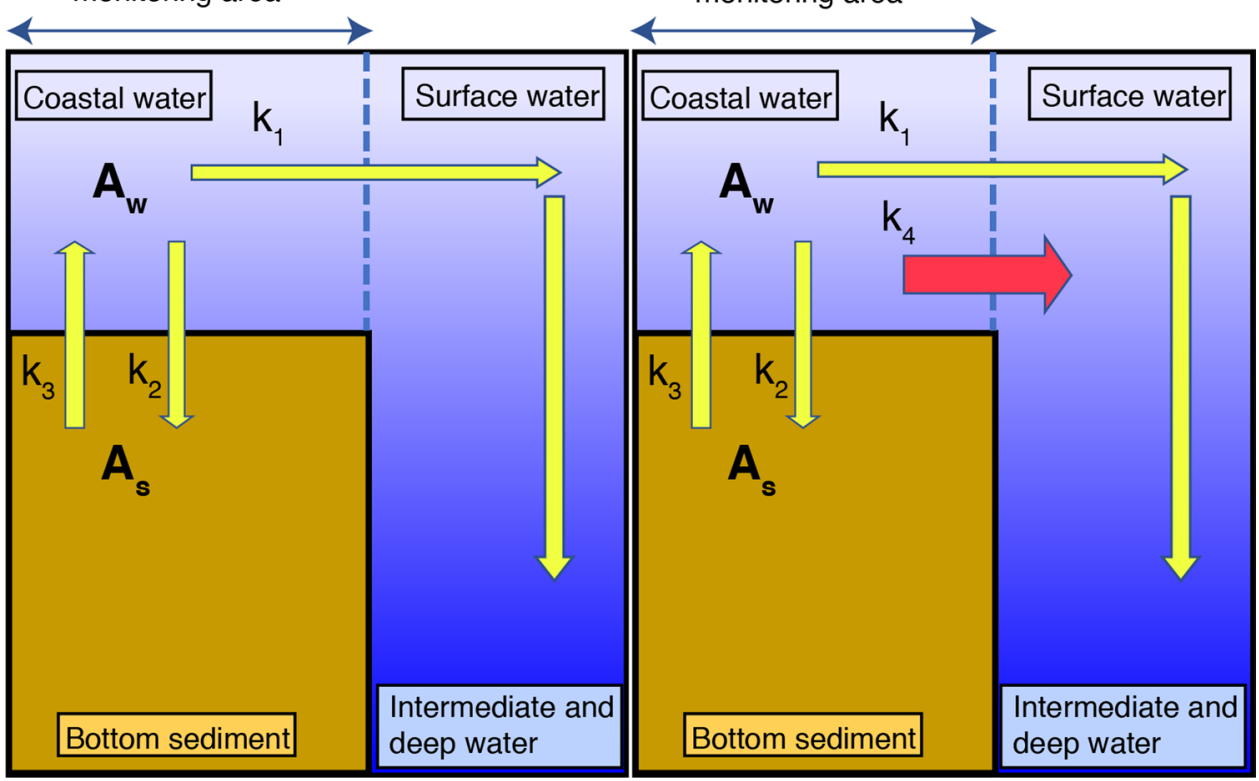

A simple mathematical model which consists of only two boxes for the regular monitoring areas, one for the seawater and the other for the bottom sediment, was constructed to evaluate the temporal change of $K_{\mathrm{d}}$ values for a period from 1984 to 2010 (pre-accident model). A schematic diagram of the model is shown in Fig. 8a. The ${ }^{137} \mathrm{Cs}$ concentration in the water in the coastal area is thought to be controlled mainly by the open ocean water mixing, as suggested by the facts that the monitoring areas are fully open to the vast reservoir of the Pacific Ocean and the Japan Sea and there is virtually no difference in effective half-lives between the coastal area (Table 1) and open ocean [18]. In other words, the main mechanism that reduces the concentration in the coastal water is due to the vertical mixing of surface water with deeper, cleaner intermediate and deep water in the open ocean.

As can be seen in Fig. 2a, the exponential decrease of ${ }^{137} \mathrm{Cs}$ concentrations in the surface and bottom waters has been observed in the coastal water so that the temporal trend of total activity of ${ }^{137} \mathrm{Cs}, A_{w}(\mathrm{~Bq})$, in a seawater box can be formulated as follows:

$A_{w}=A_{w 0} e^{-k_{1} t}$

where $A_{w 0}$ is total activity of ${ }^{137} \mathrm{Cs}$ in the seawater box on March 1, 1984 and $k_{1}$ is declining rate of the activity due to the physical decay of ${ }^{137} \mathrm{Cs}$ and water mixing with deep cleaner water in the open ocean. Obviously, the seawater box has input from the sediment and output to the sediment (Fig. 8a). However, due to the possible rapid water exchange with the open ocean which has an overwhelmingly vast mass, the two terms can be omitted from the mass balance calculation in seawater. This assumption is justified because water exchange can be expected to be the dominant mechanism to control the ${ }^{137} \mathrm{Cs}$ activity concentration in the seawater as the residence time of seawater in the continental shelf of eastern Japan has been estimated, by two independent research teams, to be 27-32 day [25] or 59 day [12], which is much shorter than the effective half-lives of ${ }^{137} \mathrm{Cs}$ in seawater (Table 1). The activity of ${ }^{137} \mathrm{Cs}$ in the sediment is then described as follows:

$\frac{\mathrm{d} A_{s}}{\mathrm{~d} t}=k_{2} A_{w}-k_{3} A_{s}$

where $A_{s}$ is total activity of ${ }^{137} \mathrm{Cs}$ in the sediment box $\left(\mathrm{Bq} \mathrm{m}{ }^{-2}\right), k_{2}$, is removal rate of ${ }^{137} \mathrm{Cs}$ from the overlying water to the bottom sediment (year ${ }^{-1}$ ), and $k_{3}$ is removal rate from the bottom sediment; $k_{2}$ is assumed to be related to the scavenging of dissolved $\mathrm{Cs}$ in seawater and adsorption to the surface of the bottom sediment particles and $k_{3}$ is controlled by physical decay of ${ }^{137} \mathrm{Cs}$, and dissolution, desorption and resuspension of the bottom sediment and its subsequent lateral transportation.

Both sides of Eq. (4) were then divided by a volume of seawater $(V, L)$ to get a concentration-based equation as follows:

$C_{w}=C_{w 0} e^{-k_{1} t}$

where $C_{w}$ and $C_{w 0}$ are ${ }^{137} \mathrm{Cs}$ concentration $\left(\mathrm{Bq} \mathrm{L}^{-1}\right)$ in seawater and ${ }^{137} \mathrm{Cs}$ initial concentration $\left(\mathrm{Bq} \mathrm{L}^{-1}\right)$ on March 1 , 
1984. In the same way, Eq. (5) was converted to a concentration-based equation:

$\frac{\mathrm{d} C_{s}}{\mathrm{~d} t}=k_{2} \frac{V}{M} C_{w}-k_{3} C_{s}$

where $C_{s}$ is ${ }^{137} \mathrm{Cs}$ concentration in sediment $\left(\mathrm{Bq} \mathrm{kg}^{-1}\right)$ and $M$ is mass ( $\mathrm{kg})$ of sediment.

Equation (6) was substituted into Eq. (7) to get Eq. (8).

$\frac{\mathrm{d} C_{s}}{\mathrm{~d} t}=k_{2} \frac{V}{M} C_{w 0} e^{-k_{1} t}-k_{3} C_{s}$

Equation (8) was solved under the conditions of $C_{s}=C_{s 0}$ and $C_{w}=C_{w 0}$ at $t=0$ on March 1,1984 . By fitting the observed data to Eq. (6), a solution of Eq. (8) and $C_{s} / C_{w}$, temporal changes of $K_{\mathrm{d}}$, were evaluated for all the regular monitoring sites around Japan and for just those in the waters off Miyagi, Fukushima and Ibaraki Prefectures. As can be seen in Supplementary Table S1, ${ }^{137} \mathrm{Cs}$ concentrations in bottom seawaters have in general lower than those in surface seawater especially in the areas with greater water depth. The geometric means of ${ }^{137} \mathrm{Cs}$ concentration in the bottom water were used for $C_{w}$ in the fitting because they may be influenced by processes in water-sediment reactions shown in Eqs. (6) and (7). By the same token, the geometric means of ${ }^{137} \mathrm{Cs}$ concentration in the surface sediments were used for $C_{s}$. Curve fitting was done using a Mathematica ${ }^{\circledR}$ command NonlinearModelFit function.

Equation (9) is the best fit curve for temporal change of $K_{\mathrm{d}(\mathrm{a})}$ for all the regular monitoring area;

$K_{\mathrm{d}(\mathrm{a})}=-430 \mathrm{e}^{-3.39 \times 10^{-4} t}+1030$

The best fit curve is also shown in Fig. 7. The average $K_{\mathrm{d}}$ values in the coastal waters around Japan increased with time from 597 on March 1, 1984 and eventually converged to 1030 . The converged $K_{\mathrm{d}}$ value was termed as $K_{\mathrm{d} \infty}$. In the system shown above, while concentrations of ${ }^{137} \mathrm{Cs}$ in both sediment and overlying water decreased with time, their ratio increased with time and will eventually converge to a constant value, $K_{\mathrm{d} \infty}$. A water-sediment system with a $K_{\mathrm{d} \infty}$ is seemingly in an equilibrium state. In the previous section, the system was assumed to be under a quasi-equilibrium but it should be rather under a dynamic equilibrium mainly controlled by the physics of seawater and bottom sediment.

Regression analysis was also done for the data obtained for the period from 1984 to 2010 in the waters off Miyagi, Fukushima, and Ibaraki Prefectures where the impacts of the FDNPP accident were the most severe afterward: Eq. (10) is the best fit curve derived and shown in Fig. 7.

$K_{\mathrm{d}(\mathrm{a})}=-1040 \mathrm{e}^{-1.28 \times 10^{-5} t}+1560$

The $K_{\mathrm{d}}$ values increased from 520 in 1984 to the $K_{\mathrm{d} \infty}$ value of 1560. A smaller increase rate and higher $K_{\mathrm{d} \infty}$ value, compared to that for all the data obtained around Japan, may be attributed to differences in physical characteristics of the bottom sediment such as silt + clay content and specific surface area: Miyagi, Fukushima, and Ibaraki areas have relatively smaller silt + clay content and smaller specific surface area (Fig. 6). However, a detailed mechanism to control the temporal change of $K_{\mathrm{d}}$ needs to be studied further.

\section{Temporal changes of $K_{\mathrm{d}(\mathrm{a})}$ since the FDNPP accident}

After March 11, 2011, mass balance of ${ }^{137} \mathrm{Cs}$ in the areas close to the accident site such as the waters off Miyagi, Fukushima, Ibaraki Prefectures was completely disturbed so that $K_{\mathrm{d}}$ in any sense of the word is inappropriate for the situation. " $K_{\mathrm{d}(\mathrm{a})}$ " used in this section is merely a ratio of ${ }^{137} \mathrm{Cs}$ concentration in sediment to that in seawater, which is assumed to be a value in the transient state of the system and may (or may not) go back to the value observed before the accident.

The calculated $K_{\mathrm{d}(\mathrm{a})}$ values varied depending on different factors which influenced the temporal changes of ${ }^{137} \mathrm{Cs}$ activity concentrations in bottom seawater and sediments.
Fig. 9 Temporal change of normalized $K_{\mathrm{d}(\mathrm{a})}$ after the accident in the regular monitoring areas. Line plots were used for the data from the areas where the impact of the accident was the highest (see Fig. 2)

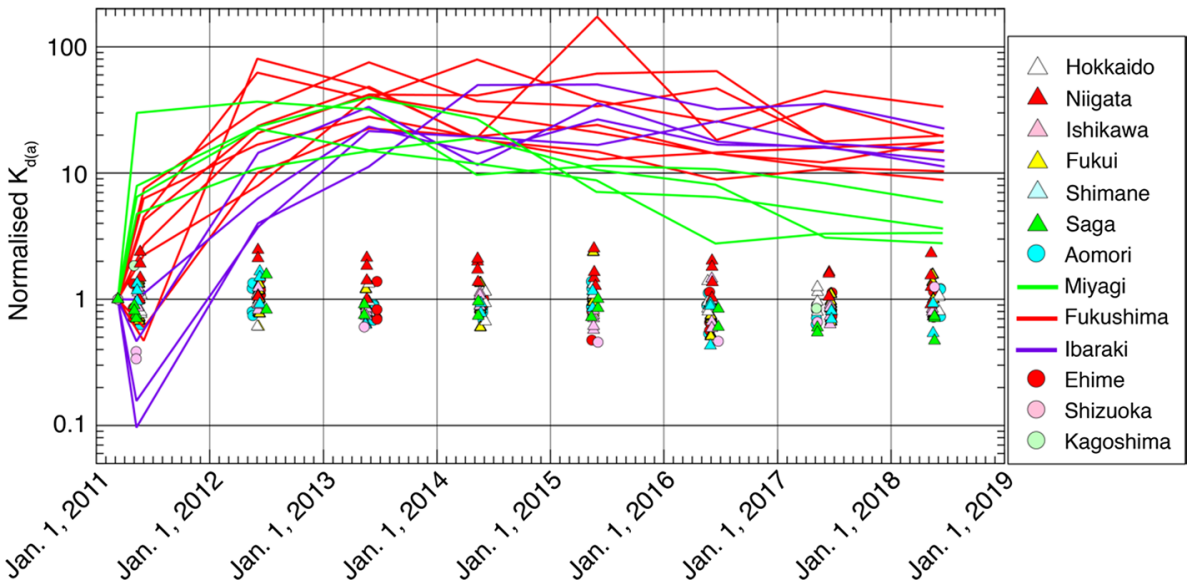


To compare temporal trends and geographical variation of $K_{\mathrm{d}(\mathrm{a})}$ among the monitoring sites, a calculated post-accident $K_{\mathrm{d}(\mathrm{a})}$ value was divided by the pre-accident 5 year average to get a normalized $K_{\mathrm{d}(\mathrm{a})}$. The normalized $K_{\mathrm{d}(\mathrm{a})}$ was set at a value of 1 for March 11, 2011 (Fig. 9). The impact of the FDNPP accident was only evident in the $K_{\mathrm{d}(\mathrm{a})}$ values of Miyagi, Fukushima, and Ibaraki Prefectures although the patterns of temporal changes differed among the three areas. For the data from the Niigata area (Fig. 2b), there were relatively higher normalized $K_{\mathrm{d}(\mathrm{a})}$ values than those of the rest of the sites for the monitoring period due to the possible inflow of Fukushima-derived ${ }^{137} \mathrm{Cs}$ via riverine transportation [26]. Whilst the normalized $K_{\mathrm{d}(\mathrm{a})}$ values in the Miyagi area rose by at most 30-fold in two months after the FDNPP accident, they dropped by a factor of ten in Ibaraki Prefecture in almost the same period. The values at two sites in the Fukushima area decreased by $50 \%$ and those at the remaining six sites increased. Upon arrival of the contaminated water, the $K_{\mathrm{d}(\mathrm{a})}$ was thought to decrease because most of the sampled bottom sediment was not yet contaminated [20]. Schematic diagrams for temporal changes of ${ }^{137} \mathrm{Cs}$ activity concentration in seawater and bottom sediments, and $K_{\mathrm{d}(\mathrm{a})}$ are presented in Fig. 10. The contaminated water mass migrated to the north initially after the FDNPP accident, and then part of the contaminated water mass moved to the south [9]. Considering the pathway of the polluted water mass, a decrease in the $K_{\mathrm{d}(\mathrm{a})}$ (at around $t_{1}$ in Fig. 10) should have occurred before the first samples were taken in Miyagi and part of Fukushima Prefectures. In other words, the samples were collected after around $t_{2}$ in Fig. 10 when the ${ }^{137} \mathrm{Cs}$ in

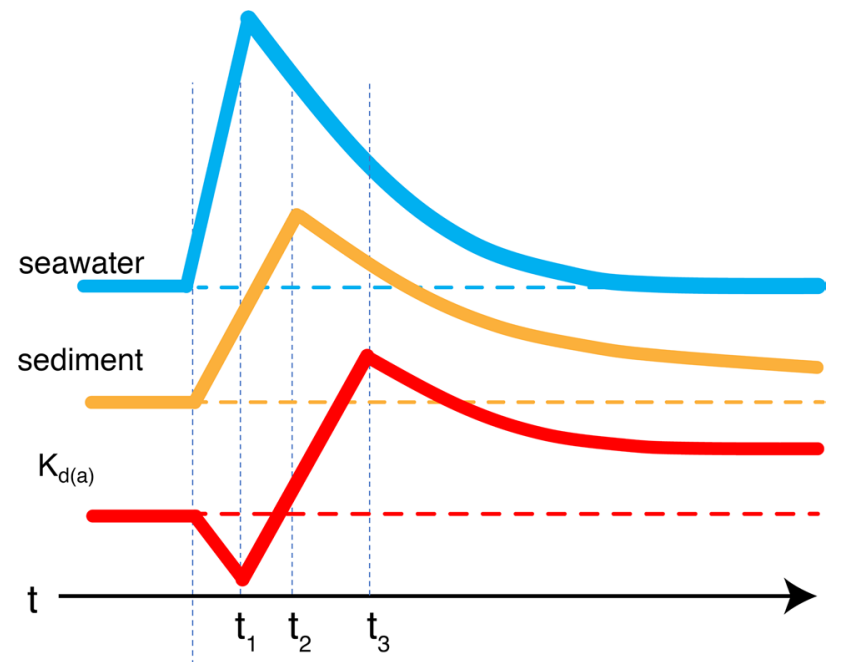

Mar. 11, 2011

Fig. 10 Schematic diagram of temporal changes of ${ }^{137} \mathrm{Cs}$ concentrations in seawater and sediment, and $K_{\mathrm{d}(\mathrm{a})}$ after the accident in the waters off Fukushima and nearby prefectures. " $t_{1}$ ", " $t_{2}$ ", and " $t_{3}$ " illustrates times when each curve reaches at its maximum after the accident sediment reached the maximum. Since the contaminated water arrived later at the southern part of the monitoring area, a significant decrease of $K_{\mathrm{d}(\mathrm{a})}$ occurred for Ibaraki, i.e., the samples were taken at around $t_{1}$ when the ${ }^{137} \mathrm{Cs}$ concentration in seawater was the highest. Subsequently, the $K_{\mathrm{d}(\mathrm{a})}$ in all three areas became almost constant or slightly declined. Even among the three areas affected by the FDNPP accident up to 2018 , the $K_{\mathrm{d}(\mathrm{a})}$ values varied about ten-fold.

The $K_{\mathrm{d}(\mathrm{a})}$ values based on the extended monitoring are shown in Fig. 3c. They ranged from $10^{2}$ to $\sim 10^{5}$. Their geometric mean started increasing from $\sim 5000$ in September 2011 and reached the maximum of $\sim 10^{4}$ in 2013. After that, the mean gradually decreased by variable degrees.

A post-accident model similar to the one described by Eqs. (4)-(8) is presented to elucidate the temporal change of $K_{\mathrm{d}(\mathrm{a})}$ following the accident. A schematic diagram for the model is shown in Fig. 8 b. ${ }^{137} \mathrm{Cs}$ newly added to the seawater decreased in a different way than the one described for the pre-accident model; it was most likely by dispersion to the surface water in the open ocean [e.g., 27]. The temporal change of total ${ }^{137} \mathrm{Cs}$ activity in the seawater box can be, thus, expressed as follows:

$A_{w}=A_{w 1} e^{-k_{1} t}+A_{w 2} e^{-k_{4} t}$

where $A_{w 1}$ and $A_{w 2}$ are activities of ${ }^{137} \mathrm{Cs}(\mathrm{Bq})$ on March 11, 2011 in the water derived from global fallout of atmospheric nuclear weapons testing and the FDNPP accident, respectively, and $k_{4}$ is the decrease rate of the latter component. Equation (11) can be rewritten in the same way as Eq. (4).

$C_{w}=C_{w_{1}} e^{-k_{1} t}+C_{w_{2}} e^{-k_{4} t}$

Change of Cs activity in sediment was expressed identically to that of Eq. (7).

$\frac{\mathrm{d} A_{s}}{\mathrm{~d} t}=k_{2} A_{w}-k_{3} A_{s}$

Equations (12) and (13) are used to express the temporal change of Cs concentration in sediment as below;

$\frac{\mathrm{d} C_{s}}{\mathrm{~d} t}=k_{2} \frac{V}{M}\left(C_{w 1} e^{-k_{1} t}+C_{w 2} e^{-k_{4} t}\right)-k_{3} C_{s}$

Temporal change of $K_{\mathrm{d}(\mathrm{a})}$ after the accident can then be calculated by division of Eq. (12) by the solution of Eq. (14).

$K_{d(a)}=\frac{C_{s}}{C_{w}}$

Equations (12), (14) and (15) were fitted to geometric means of ${ }^{137} \mathrm{Cs}$ concentrations in bottom water and sediments, and their $K_{\mathrm{d}(\mathrm{a})}$ values were obtained in the waters off Miyagi, Fukushima, Ibaraki and Chiba Prefectures (Fig. 1b, the extended monitoring area). The data used for the regression 


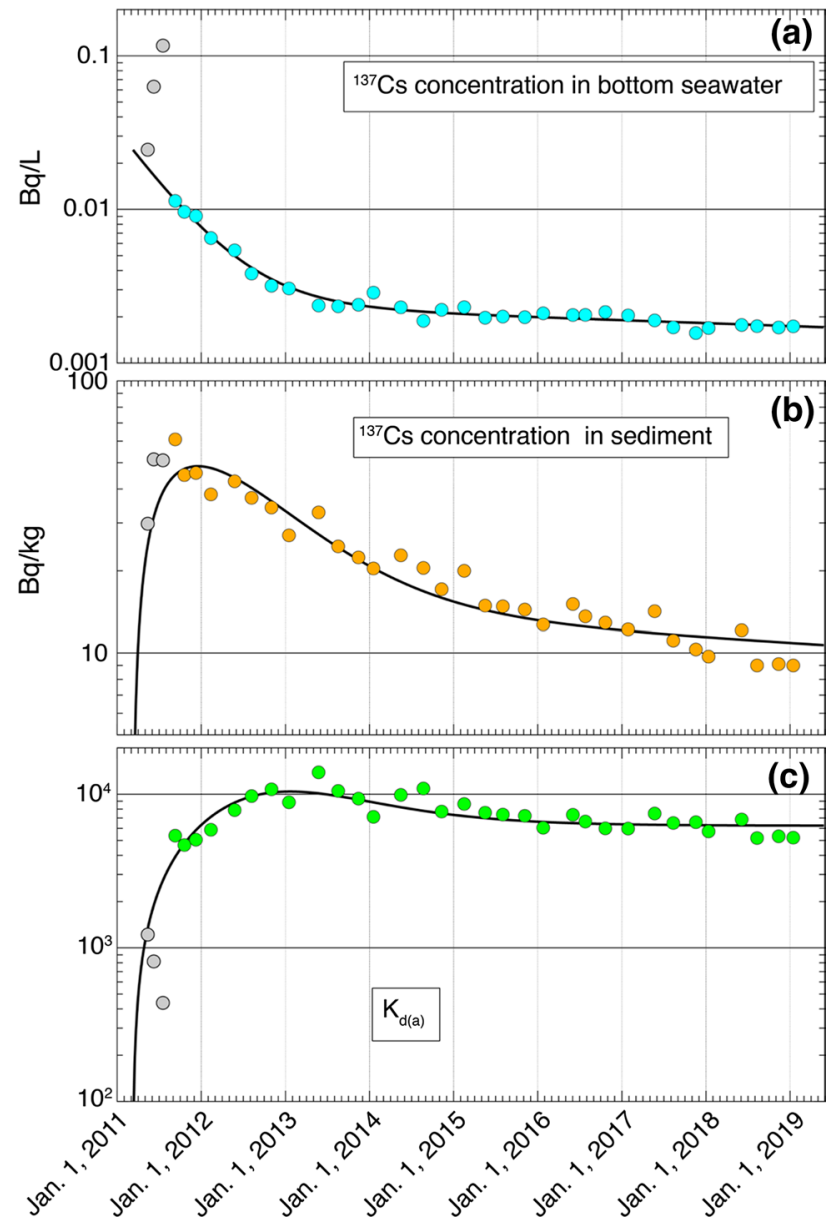

Fig. 11 Temporal changes in geometric means of ${ }^{137} \mathrm{Cs}$ activity concentrations in bottom seawater (a) and sediment (b), and of $K_{\mathrm{d}(\mathrm{a})}(\mathbf{c})$ in the extended monitoring areas after the FDNPP accident. The lines indicate the best-fit curves based on the model calculation. Data shown in grey marker are derived from a small dataset and were not included in the regression analysis

analysis covered a time span from September 2011 to January 2019 (i.e., after $t_{2}$ in Fig. 10).

The following is the best fit curve for the $K_{\mathrm{d}(\mathrm{a})}$;

$K_{\mathrm{d}(\mathrm{a})}=6240+\frac{-174+112000 e^{0.00149 t}}{8.59+e^{0.00465 t}}$

Equation (16) is also plotted in Fig. 11c. It should be noted that the grey marks in the figures were calculated from limited data sets so that they were omitted from the curve fittings. As shown in the previous sections, ${ }^{137} \mathrm{Cs}$ concentrations in seawaters derived from the accident decreased more quickly than those in sediments; as of January 2019, the former were almost at the same level as before the accident and the latter were still one order of magnitude higher (Fig. 2). Consequently, the best-fit curve for $K_{\mathrm{d}(\mathrm{a})}$ reached the maximum $(10,400)$ around January 2013 and decreased gradually. The curve fittings revealed that even though the concentrations of ${ }^{137} \mathrm{Cs}$ in bottom seawater and surface sediment have decreased with time, $K_{\mathrm{d}(\mathrm{a})}$ will not return to the pre-accident level ( 600$)$, but converge to the $K_{\mathrm{d} \infty}$ of 6240 in the waters off Fukushima and nearby prefectures.

The model presented here for the post-accident situation was applied to a period from $t_{2}$ in Fig. 10 to present based on the assumption that ${ }^{137} \mathrm{Cs}$ input to the monitoring area was instantaneous. Thus, the continuing input of ${ }^{137} \mathrm{Cs}$ from the accident site [12] to the extended monitoring area was ignored in Eqs. (11) and (12). Buesseler et al. [28] estimated that ${ }^{137} \mathrm{Cs}$ input was five to six orders of magnitude higher for the first month after the initial release than that of 2013 and 2014. Although the average concentration in seawater was still higher than the pre-accident level as of 2018, that was due to the continuing release from the accident site, the mass balance of ${ }^{137} \mathrm{Cs}$ in the coastal waters should not have been affected by this release. Addition of a third term to Eqs. (11) and (12) would have changed the shape of the best-fit curve initially. However, the temporal trend of $K_{\mathrm{d}(\mathrm{a})}$ values should not be affected significantly because most of the ${ }^{137} \mathrm{Cs}$ in the sediment was likely brought to the site in the first several months and release of ${ }^{137} \mathrm{Cs}$ from the accident site has been decreasing so that the continuing release of ${ }^{137} \mathrm{Cs}$ from the accident site should be negligible in the mass balance calculation for the seawater-sediment system in the water off Fukushima and nearby prefectures.

The post-accident model above is site/event specific. Oceanographic conditions, release modes of radionuclides (continuous or instantaneous), and magnitude of environmental contamination as well as the physical characteristics of bottom sediments may be key factors to elucidate the behavior of ${ }^{137} \mathrm{Cs}$ in coastal waters.

\section{Conclusions}

$K_{\mathrm{d}}$ values for ${ }^{137} \mathrm{Cs}$ in the coastal waters around Japan have been calculated for 1984-2010 when only global fallout was the dominant source of ${ }^{137} \mathrm{Cs}$ to the marine environment. They varied largely in a range from 175 to 7541 with a geometric mean of 920 . The variation was well correlated with the specific surface area of the bottom sediments. Thus, while $K_{\mathrm{d}}$ values were suggested to be determined initially by the surface reaction between bottom sediments and overlying seawater, the temporal change of the values was also observed; they increased with time and converged to $K_{\mathrm{d}(\mathrm{a}) \infty}$. Temporal change of $K_{\mathrm{d}(\mathrm{a})}$ was also observed following the Fukushima DNPP accident. $K_{\mathrm{d}(\mathrm{a})}$ increased initially and then decreased; it will finally converge to $K_{\mathrm{d}(\mathrm{a}) \infty}$ which will be about ten times the pre-accident value.

The models presented here were obviously simplified for systems which have highly variable parameters. Application 
of average values to these models was one reason to avoid complexity. In addition, diagenetic processes such as a two-step process including fast and slow reversible adsorption-desorption in sediments and vertical migration of ${ }^{137} \mathrm{Cs}$ as particles or a dissolved form in the pore space were not taken into consideration [e.g., 29, 30]. However, the conclusions drawn from the simple pre- and post-accident models based on geometric means in a wide area should hold in general; they are: (1) even before the Fukushima accident the water-sediment system with respect to ${ }^{137} \mathrm{Cs}$ had been in a transient state with a temporally changing $K_{\mathrm{d}}$ approaching $K_{\mathrm{d} \infty}$; and (2) once significant amounts of ${ }^{137} \mathrm{Cs}$ were added to the system, the system shifted to a newly established transient state for the $K_{\mathrm{d}(\mathrm{a})}$ values approaching a higher $K_{\mathrm{d} \infty}$ value. Such long-term retention of ${ }^{137} \mathrm{Cs}$ (over a decadal time scale) would be consistent with data observed in the US nuclear test grounds of the Bikini and Enewetak Atolls where the ratios of activity concentration of ${ }^{137} \mathrm{Cs}$ in sediment to that in seawater remain elevated more than 60 years after the tests [31].

Acknowledgements The data presented here were obtained during 35 years of the monitoring program, which were initially done under contract with the Ministry of Education, Culture, Sports, Science and Technology (1984-2013) and are presently done under the Secretariat of the Nuclear Regulation Authority (2013-present). The authors would like to express their sincere appreciation to all the people (too many to name here) in the Marine Ecology Research Institute who have been involved in these activities. Without their contributions, such a highly indispensable database for marine radioactivity would have never existed. The authors are grateful to Dr. M. Yamada for his helpful comments and suggestions.

Open Access This article is distributed under the terms of the Creative Commons Attribution 4.0 International License (http://creativeco mmons.org/licenses/by/4.0/), which permits unrestricted use, distribution, and reproduction in any medium, provided you give appropriate credit to the original author(s) and the source, provide a link to the Creative Commons license, and indicate if changes were made.

\section{References}

1. Takata H, Tagami K, Aono T, Uchida S (2014) Distribution coefficients $\left(\mathrm{K}_{\mathrm{d}}\right)$ of strontium and significance of oxides and organic matter in controlling its partitioning in coastal regions of Japan. Sci Total Environ 490:979-986

2. Takata H, Aono T, Tagami K, Uchida S (2016) A new approach to evaluate factors controlling elemental sediment-seawater distribution coefficients $(\mathrm{Kd})$ in coastal regions, Japan. Sci Total Environ 543:315-325

3. Li YY, Burkhardt L, Buchholtz M, O’Hara P, Santschi P (1984) Partition of radiotracers between suspended particles and seawater. Geochim Cosmochim Acta 48:2011-2019

4. Børretzen P, Salbu B (2002) Fixation of Cs to marine sediments estimated by a stochastic modeling approach. J Environ Radioact 61:1-20
5. IAEA (2004) Sediment distribution coefficients and concentration factors for biota in the marine environment. Technical report series no. 422

6. Kasamatsu F, Inatomi N (1998) Effective environmental half-lives of ${ }^{90} \mathrm{Sr}$ and ${ }^{137} \mathrm{Cs}$ in the coastal seawater of Japan. J Geophys Res 103:1209-1217

7. Watabe T, Oikawa S, Isoyama N, Suzuki C, Misonoo J, Morizono S (2013) Spatiotemporal distribution of $137 \mathrm{Cs}$ in the sea surrounding Japanese Islands in the decades before the disaster at the Fukushima Daiichi Nuclear Power Plant in 2011. Sci Total Environ 463(464):913-921

8. Takata H, Kusakabe M, Inatomi N, Ikenoue T (2018) Appearances of Fukushima Daiichi nuclear power plant-derived ${ }^{137} \mathrm{Cs}$ in coastal waters around Japan: results from marine monitoring off nuclear power plants and facilities, 1983-2016. Environ Sci Technol 52:2629-2637

9. Oikawa S, Takata H, Watabe T, Misonoo J, Kusakabe M (2013) Distribution of the Fukushima-derived radionuclides in seawater in the Pacific off the coast of Miyagi, Fukushima, and Ibaraki Prefectures, Japan. Biogeosciences 10:5031-5047

10. Kusakabe M, Oikawa S, Takata H, Misonoo J (2013) Spatiotemporal distributions of Fukushima-derived radionuclides in nearby marine surface sediments. Biogeosciences 10:5019-5030

11. Kusakabe M, Inatomi N, Takata H, Ikenoue T (2017) Decline in radiocesium in seafloor sediments off Fukushima and nearby prefectures. J Oceanogr 73:529-545

12. Takata H, Kusakabe M, Inatomi N, Ikenoue T, Hasegawa K (2016) The contribution of sources to the sustained elevated inventory of ${ }^{137} \mathrm{Cs}$ in offshore waters east of Japan after the Fukushima Dai-ichi Nuclear Power Station Accident. Environ Sci Technol 50:6957-6963

13. https://radioactivity.nsr.go.jp/en/list/205/list-1.html. Accessed 24 Sept 2019

14. Kasamatsu F, Ueda Y, Tomizawa T, Nonaka N, Nagaya Y (1994) Preliminary report on radionuclide concentrations in the bottom waters at the entrance of Wakasa bay with special reference to the Japan sea proper water. J Oceanogr 50:589-598

15. Kumamoto Y, Yamada M, Aoyama M, Hamajima Y, Kaeriyama H, Nagai H, Yamagata T, Murata A, Masumoto Y (2019) Radiocesium in North Pacific coastal and offshore areas of Japan within several months after the Fukushima accident. J Environ Radioact 198:79-88

16. Kanda J (2013) Continuing ${ }^{137}$ Cs release to the sea from the Fukushima Dai-ichi Nuclear Power Plant through 2012. Biogeosciences 10:6107-6113

17. Tsumune D, Tsubono T, Aoyama M, Uematsu M, Misumi K, Maeda Y, Yoshida Y, Hayami H (2013) One-year, regional-scale simulation of ${ }^{137} \mathrm{Cs}$ radioactivity in the ocean following the Fukushima Dai-ichi Nuclear Power Plant accident. Biogeosciences 10:5601-5617

18. Povinec PP, Aarkrog A, Buesseler KO, Delfanti R, Hirose K, Hong GH, Ito T, Livingston HD, Nies H, Noshkin VE, Shima S, Togawa $\mathrm{O}(2005){ }^{90} \mathrm{Sr},{ }^{137} \mathrm{Cs}$ and ${ }^{239,240} \mathrm{Pu}$ concentration surface water time series in the Pacific and Indian Oceans-WOMARS results. J Environ Radioact 81:63-87

19. Hirose K, Aoyama M (2003) Analysis of ${ }^{137} \mathrm{Cs}$ and ${ }^{239,240} \mathrm{Pu}$ concentrations in surface waters of the Pacific Ocean. Deep-Sea Res II 50:2675-2700

20. Boyer P, Wells C, Howard B (2018) Extended Kd distributions for freshwater environment. J Environ Radioact 192:128-142

21. He Q, Walling DE (1996) Interpreting particle size effects in the adsorption of ${ }^{137} \mathrm{Cs}$ and unsupported ${ }^{210} \mathrm{~Pb}$ by mineral soils and sediments. J Environ Radioact 30:117-137

22. Kershaw P, Pentreath RJ, Woodhead DS, Hunt GJ (1992) A review of radioactivity in the Irish Sea. A report prepared for the Marine Pollution Monitoring Management Group. Ministry of 
Agriculture, Fisheries and Food Aquatic Environment Monitoring report number 32. MAFF, Lowestoft

23. MacKenzie AB, Cook GT, McDonald P, Jones SR (1998) The influence of mixing timescales and re-dissolution processes on the distribution of radionuclides in the northeast Irish Sea sediments. J Environ Radioact 39:35-53

24. Uchida S, Tagami K (2017) Comparison of coastal area sedimentseawater distribution coefficients $\left(\mathrm{K}_{\mathrm{d}}\right)$ of stable and radioactive $\mathrm{Sr}$ and Cs. Appl Geochem 85:148-153

25. Charette MA, Breier CF, Henderson PB, Pike SM, Rypina II, Jayne SR, Buesseler KO (2013) Radium-based estimates of cesium isotope transport and total direct ocean discharges from the Fukushima Nuclear Power Plant accident. Biogeosciences 10:2159-2167

26. Inoue $M$, Uemura $H$, Kofuji $H$, Fujimoto $K$, Takata $H$, Shirotani Y, Kudo N, Nagao S (2017) Spatial variation in low-level ${ }^{134} \mathrm{Cs}$ in the coastal sediments off central Honshu in the Sea of Japan: implications for delivery, migration, and redistribution patterns. J Oceanogr 73:571-584

27. Aoyama M, Hamajima Y, Hult M, Uematsu M, Oka E, Tsumune $\mathrm{D}$, Kumamoto Y (2016) ${ }^{134} \mathrm{Cs}$ and ${ }^{137} \mathrm{Cs}$ in the north pacific ocean derived from the March 2011 TEPCO Fukushima Dai-ichi
Nuclear Power Plant accident, Japan. Part one: surface pathway and vertical distributions. J Oceanogr 72:53-65

28. Buesseler K, Dai M, Aoyama M, Benitez-Nelson C, Charmasson S, Higley K, Maderich V, Masqué P, Oughton D, Smith JN (2017) Fukushima Daiichi-derived radionuclides in the ocean: transport, fate, and impacts. Annu Rev Mar Sci 9:173-203

29. Maderich V, Jung KT, Brovchenko I, Kim KO (2017) Migration of radioactivity in multi-fraction sediments. Environ Fluid Mech 17:1207-1231

30. Periáñez R, Brovchenko I, Jung KT, Kim KO, Maderich V (2018) The marine $\mathrm{K}_{\mathrm{d}}$ and water/sediment interaction problem. J Environ Radioact 192:635-647

31. Buesseler KO, Charette MA, Pike SM, Henderson PB, Kipp LE (2018) Lingering radioactivity at the Bikini and Enewetak Atolls. Sci Total Environ 621:1185-1198

Publisher's Note Springer Nature remains neutral with regard to jurisdictional claims in published maps and institutional affiliations. 